stand-alone woodstoves and also transform the huge amounts of waste energy from industrial furnaces and power plants.

\section{The Future of Thermoelectric Materials}

The future expansion of thermoelectric energy conversion technologies is tied primarily to enhanced materials performance along with better thermal management design. The best thermoelectric material should behave as a so-called phononglass-electron-crystal; that is, it should minimally scatter electrons, as in a crystalline material, whereas it should highly scatter phonons, as in an amorphous material. Materials researchers are now investigating several systems of materials including typical narrow-bandgap semiconductors (half-Heusler alloys), oxides, and cage-structure materials (skutterudites and clathrates). ${ }^{4}$ More exotic structures that exhibit reduced dimensionality and nanostructures have been the focus of much recent research, including superlattices, quantum dots, and nanodot bulk materials. Also, recent progress in nanocomposites, mixtures of nanomaterials in a bulk matrix, has generated much interest and hope for these materials. ${ }^{4}$ The emerging field of these thermoelectric nanocomposites appears to be one of the most promising recent research directions. Such nanocomposites could allow for higher $Z T$ values by reducing thermal conductivity while maintaining favorable electronic properties. With new higher efficiency materials, the field of harvesting waste energy through thermoelectric devices will become more prevalent.

The most stable, long-term, and readily available worldwide energy source is that of solar energy. The issue has always been low-cost transformation and storage. Other alternative energy technologies such as fuel cells, wind energy, and thermoelectrics will provide some assistance in meeting our future energy needs. Many hybrid systems will be needed, and thermoelectrics is able to work in tandem with many of these other technologies, especially solar as it can use the heat source provided by solar radiation. Over the past decade, thermoelectric materials have been developed with $Z T$ values that are a factor of 2 larger than those of previous materials. Another $50 \%$ increase in $Z T$ (to $Z T \approx 3$ ) with the appropriate material characteristics and costs will position thermoelectrics to be a significant contributor to our energy needs, especially in waste heat or solar energy conversion. The likelihood of achieving these goals appears to be within reach in the next several years. Furthermore, some contribution from many of these alternative energy technologies such as thermoelectrics will be needed in order to fulfill the world's future energy needs.

\section{References}

1. T.J. Seebeck, Abh. K. Akad. Wiss. 265 (Berlin, 1823).

2. A.F. Ioffe, Semiconductor Thermoelements and Thermoelectric Cooling (Infosearch, London, 1957).

3. H.J. Goldsmid, R.W. Douglas, Br. J. Appl. Phys. 5, 386 (1954).

4. T.M. Tritt, M.A. Subramanian, MRS Bull. 31 (3), 188 (2006); six articles and all references therein.

5. J. Yang, T. Caillat, MRS Bull. 31 (3), 224 (2006).

6. S. Maneewan, J. Hirunlabh, J. Khedari, B. Zeghmati, S. Teekasap, Solar Energy 78, 495 (2005).

\title{
Off-Grid Solar for Rural Development
}

\author{
Wole Soboyejo (Princeton University, USA) and Roger Taylor (National Renewable Energy Laboratory, \\ USA)
}

The World Bank estimates that over two billion people on the planet live their daily lives without access to basic, reliable electric services. ${ }^{1}$ Rural populations in Africa, Latin America, Asia, and island nations need clean water, health services, communications, and light at night. Small, simple, solar electric systems are part of the solution-increasing the quality of life, often at a cost that is less than what is presently being spent for kerosene, dry-cell batteries, and the recharging of automotive batteries that must be lugged to the nearest town on a weekly basis (see Figure 1).

Better technology through advanced materials can reduce costs and improve both the performance and reliability of solar electric systems, but in the field, nothing is "maintenance-free." A loose connection or a dry battery can quickly disable the most sophisticated system. The success of solar systems in remote areas depends not only on competitive cost, but also on the human infrastructure needed to deploy and maintain the systems. Work over the past two decades in pilot deployments of solar photovoltaic (PV) systems has highlighted a few issues that must be addressed if solar PV is to provide the promise of cost-effective, reliable energy solutions in remote regions. ${ }^{2}$

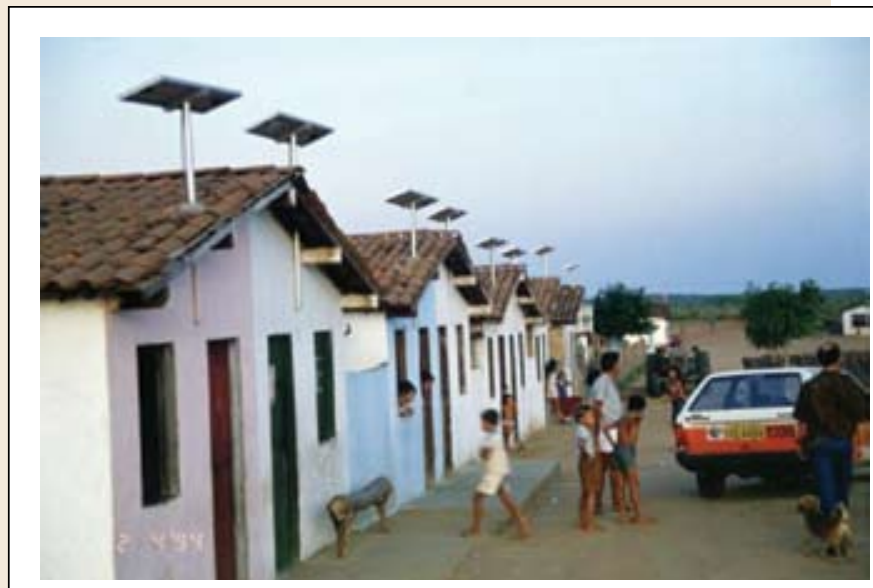

Figure 1. In the village of Irapura, Ceara, Brazil, homes were fitted with $50 \mathrm{~W}$ solar panels for night lighting, television, and radio. A battery stores electricity generated by the solar panel for use at night. (Photograph by Roger Taylor.) 
Although PV panels are close to maintenance-free, PV systems are not; therefore, a maintenance support infrastructure needs to be established and nurtured. This issue must be addressed from the very conception of a project. This support infrastructure need not be complex, but it does need to be functional and appropriate for the size, complexity, and sophistication of the systems deployed. A training program with documentation that is matched to the local capabilities, regular refresher courses, planning for personnel turnover, a spare-parts inventory, component resupply, and funds for preventive and problem maintenance must all be addressed.

In small stand-alone systems for homes, schools, health clinics, water pumping, and other applications, strong efforts need to be made to decouple the concepts of electricity sales measured in pennies per kilowatt-hour from fee-for-service monthly payments. Many rural customers are already paying \$5-15/month for basic energy services that can be better met with stand-alone renewable energy systems (and without subsidies). It is often difficult to convince electric utilities and other local officials to think about an energy-services approach where customers pay a flat fee-for-service - for lighting, refrigeration, or communications, for example - instead of a per-unit price per metered kilowatt-hour.

Rural electrification generally consists of power line extension or diesel mini-grids based on an annual budget for installations. The concept of life-cycle cost analysis, which equitably compares capital-intensive versus operatingexpense-intensive technologies, is still uncommon in small consumer transactions. The concept of life-cycle costing needs to be integrated into the training of officials charged with rural electrification.

Energy-efficient end-use applications/appliances are critical to economically sized renewable energy systems. Investing in energy efficiency has much more economic value than adding generation capacity to meet the demand of inefficient appliances. It is important that a complete systems-engineering approach be maintained, attempting to deliver the best end-use service for the least overall system life-cycle cost.

The most important factor for successful implementation is a supportive, positive attitude by the rural electrification officials. The existence of a champion for solar-based rural electrification, who is in a position of authority, is required to maintain momentum during and after installation. There is no substitute for a dedicated, influential, local champion.

In order to sustain a newly implemented rural electricity system, an administrative system needs to be developed and sustained. Many rural villages have formed cooperatives for fishing, agriculture, and other economic development activities. The specific electricity administrative solution will be regional or village-dependent or both. Although a number of models have been successful, care is needed in matching the administrative system to the village social dynamics.

Renewable energy solutions for village power applications can be economical, functional, and sustainable. Pilot projects are an appropriate step in the development of a commercially viable market for renewable rural solutions. Moreover, a significant number of rural electrification projects are under way that employ various technologies, delivery mechanisms, and financing arrangements. These projects, if properly evaluated and communicated-so that their lessons are incorporated in future projects and programs - can lead the way to a future that includes a robust opportunity for cost-effective, renewablesbased village power systems, bringing modern electric services to rural populations at a cost that is competitive with or less than those of both central-station generation and stationary diesel generators.

In an effort to explore the sustainable application of solar energy in rural settings, a number of applications have been explored recently by the U.S./Africa Materials Institute (USAMI) at Princeton University, Princeton, New Jersey, and the Global Development Network (GDN), based in New Delhi, India. These include community-based solar energy approaches at an ecotourism lodge in Il Motiok, Kenya; rural electrification of the Aang Serian School in Eluai village, Monduli District, Tanzania; and a solar refrigeration project for cooling and preserving vaccines during transportation to remote and rural parts of Kenya that cannot be reached by land rover. The last project was undertaken in close collaboration with the Art Center College of Design, Pasadena, California. In all cases, the projects have been designed to provide electricity to people living on less than a dollar a day. Hence, sustainability was considered carefully in the design and installation of the systems.

In the case of the ecotourism lodge in Il Motiok (Figure 2), a community-based solar system was provided to a women's group that had set up an ecotourism lodge to attract local and international tourists to a remote off-grid region in the Laikipia district in Kenya. The solution involved the use of high-efficiency crystalline solar cells, a charge controller, and two locally made 100 amp-hours (Ah) deep-cycle batteries that were used to develop a small station for the charging of solar lanterns (light-emitting devices or LEDs). Each charge was found to provide up to five days of lighting for local families in the local village. The lanterns were also used by guests who come largely from Europe and North America to enjoy the wildlife and local culture in the Laikipia plateau. The system is sustainable because the local people derive income from the ecotourism lodge. They also charge a small fee to charge cell phones that are now a common feature of life in most parts of rural Africa. Above all, the local managers of the charging station were trained in solar maintenance and installation after the system was installed. This provided a much better alternative to driving $2 \mathrm{~h}$ to the nearest town, Nanyuki, to charge the solar lanterns and cell phones for local use.

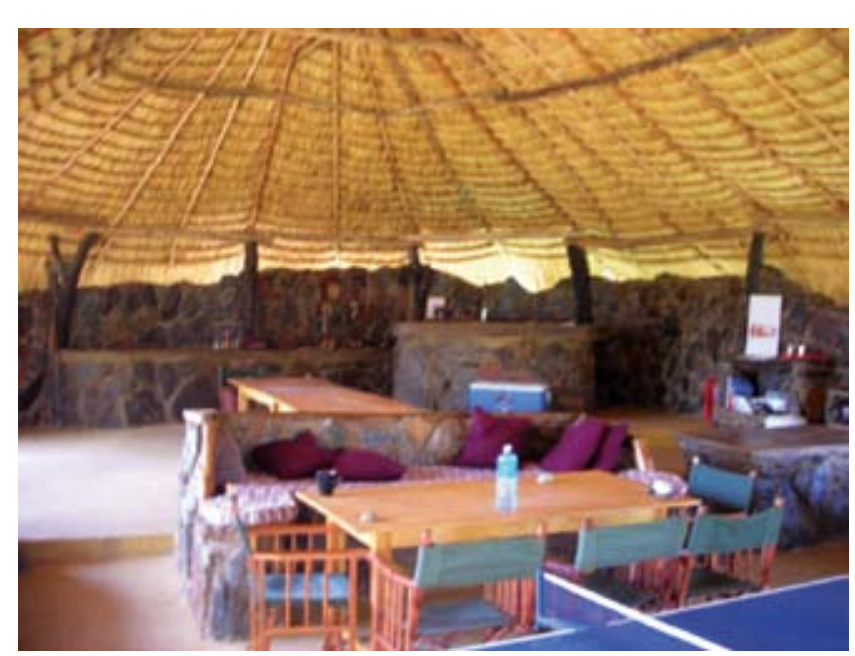

Figure 2. Solar-powered light-emitting devices that provide five days of light after each charge at the OI Gaboli Community Lodge, an ecotourism lodge in II Motiok, Kenya. 
The experience of the Noonkodin Secondary School, which is run by the Aang Serian Community, is also of some interest. This is a school that was established to provide high school education to the nomadic Maasai and Hazabe people within the context of their local cultures and indigeneous knowledge. Photovoltaic systems (Figure 3) were installed to provide electricity to the boarding house, classrooms, and homes of the teachers and headmaster. The local people and the staff at the school were also trained to maintain the system, which provided rural electrification for the first time to the people of the village. As income is earned from the school, the system can be maintained to provide for the longterm electricity needs of the school and the local community.

In the area of global health, solar energy provides a crucial means of preserving vaccines in rural off-grid areas. Because of the high energy consumption associated with refrigeration, novel system designs are needed to develop sustainable solutions for transporting vaccines to places that cannot be reached by the most rugged of land rovers. In such cases, the vaccines are often transported on camels on missions that can last up to seven days. In the case of the Mpala Clinic in Mpala, Kenya, a small group of nurses and local doctors provides healthcare to a population of about 150,000 people. Much of the communitybased care and vaccination of children, therefore, requires the preservation of vaccines. This motivated the development of a solar-powered refrigeration system that is powered by both flexible and rigid solar cells (Figure 4). The system, which includes a special camel saddle, was designed jointly by a team from the Art Center College of Design and the USAMI researchers.

Larger scale rural electrification programs have been carried out by the Solar Electric Company of India (SELCO). This company has worked with banks to provide financing schemes to enable rural people to pay for solar systems in remote villages. Such approaches have enabled village economies to grow through stimulation of nighttime trading by the provision of solar electrification. They have also enabled off-grid rural people to enjoy the benefits of solar energy at rates that can be sustained by the local economies. This has been sufficient to stimulate the sustained growth of SELCO for more than a decade.

Similar models are being explored in Nigeria, where a recent collaboration between the U.S. and Nigerian academies of science has investigated the concepts that could stimulate the establishment of science-based industries in Nigeria. Funded by the Gates Foundation as a pilot program, the group of U.S. and Nigerian scientists worked with local entrepreneurs, government representatives, and academics to explore the feasibility of establishing an off-grid solar company that could provide energy in an environment where power cuts are frequent in the urban areas, and often unavailable in the rural areas.

The U.S./Nigerian study essentially recognizes that the long-term viability of such off-grid solar companies requires the connection of solar energy to a successful business model. Furthermore, the business model must include financing

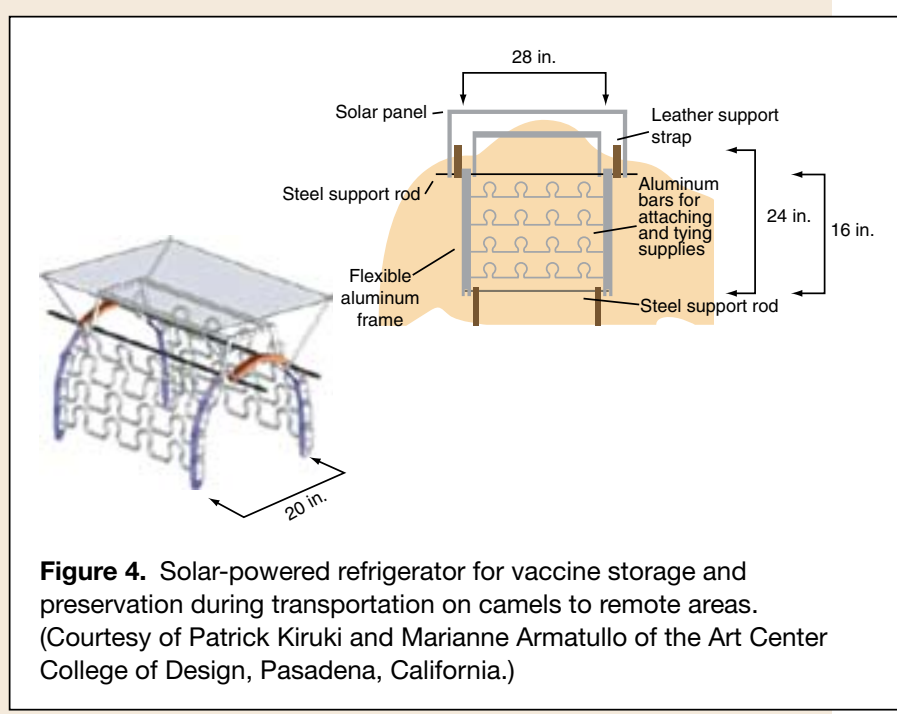

schemes through banks or community savings groups; social entrepreneurship by local companies; the integration of maintenance costs into the financing and sales agreements; and the development of local technical expertise that can install, maintain, and replace these systems over the projected system life of about 20 years.

Although these examples show how current solar energy technologies are improving the lives of off-grid rural and rural/urban people, much work is needed to develop the materials technologies that could dramatically reduce the costs of solar energy. In the short term, the lowest cost per kilowatt-hour can be achieved by the use of amorphous solar energy systems provided by thin-film deposition technologies..$^{2,3}$ However, the current-voltage characteristics of these systems are often designed to provide relatively low currents (about $1 \mathrm{~A}$ ). Hence, it is often necessary to have a greater number of amorphous solar cells (than crystalline solar cells) to provide the required amount of charge.

In the medium to long term, there is much hope that the socalled balance of system costs could be reduced by advances in battery and charge controller technologies, as well as the devel- 


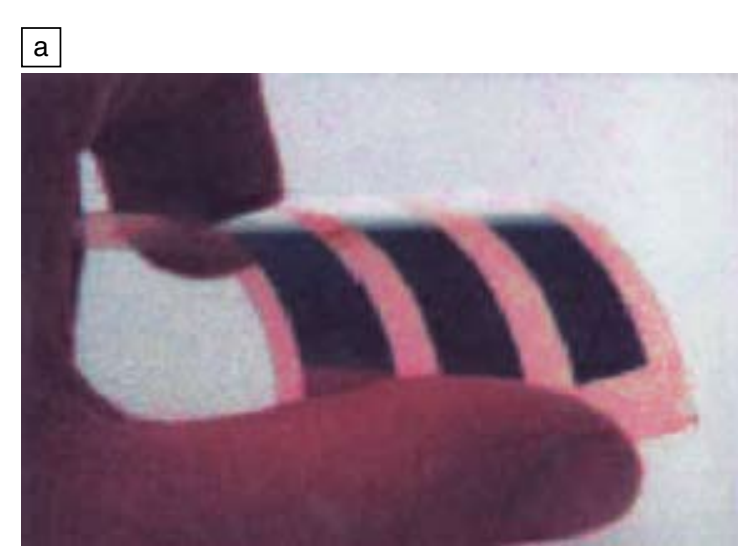

b

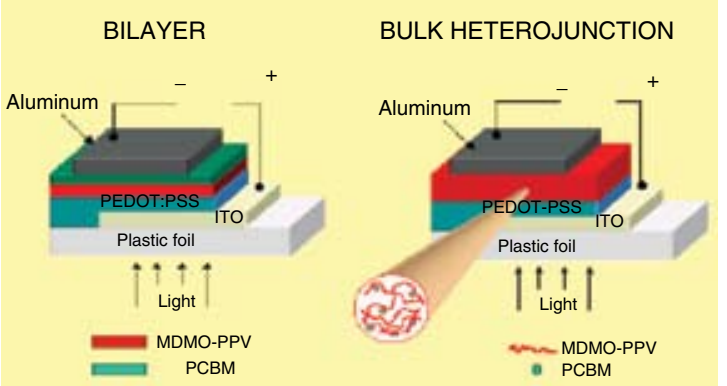

Figure 5. Organic electronic structures for rural and urban lighting: (a) flexible organic solar cells and (b) schematic of possible layered structure. Note: MDMO-PPV, poly[2methoxy-5-(3',7'-dimethyloctyloxy)-p-phenylenevinylene]; PCBM, [6,6]-phenyl C61 butyric acid methyl ester; PEDOT: PSS, poly(3,4-ethylenedioxythiophene) poly(styrenesulfonate). opment of organic electronic structures that could provide the potential for low-cost solar energy. In the long term, such advances have the potential to reduce the cost of solar cells by a factor of 10 . Such a reduction could greatly facilitate the global applications of solar energy in both the developed and the developing world. However, additional research is needed to improve the efficiencies of the solar cells and the stability of the organic electronic structures for rural and urban electrification (Figure 5). ${ }^{4}$ Ongoing materials research efforts in this area are motivated by issues related to charge transport across bilayers and bulk heterojunctions and polymer/interfacial stability. This is especially true for organic solar cells and organic light-emitting devices, which are essentially solar cells run in reverse.

Before closing, it is important to note that recent advances in research have resulted in a rapid increase in the efficiencies of organic solar cells from about $1 \%$ to $6 \% .{ }^{5}$ If the current trend continues, it is likely that organic electronic structures could soon become competitive alternatives to commercial siliconbased solar cells that have efficiencies between $5 \%$ and $15 \%$. This has motivated an integrated research effort in the global materials community.

\section{Acknowledgments}

W.O.S. acknowledges the financial support of USAMI through a grant from the Division of Materials Research (DMR 0231418) of the National Science Foundation. Appreciation is extended to the Program Manager, Dr. Carmen Huber, for her encouragement and support.

\section{References}

1. Improving Lives: World Bank Group Progress on Renewable Energy and Energy Efficiency in Fiscal Year 2006 (World Bank Group, Washington, DC December 2006).

2. M. Hankins, Solar Electric Systems for Africa (Commonwealth Science Council, London, 1995).

3. T. Otiti, W.O. Soboyejo, Perspect. Glob. Dev. Technol. 5, 69 (2006).

4. S. Forrest, P. Burroughs, M. Thompson, IEEE Spectr. 37 (August 2000).

5. K. Kim, J. Liu, M.A.G. Namboorthiry, D.L. Carroll, Appl. Phys. Lett. 90 , 16311 (2007)

\title{
The 3 GW Initiative
}

\author{
Tim Palucka (Science Writer, USA)
}

California continues its tradition of leading the United States in environmental stewardship through the California Solar Initiative (CSI), a \$3.3 billion program established in January 2006. The goal is to generate $3 \mathrm{GW}$ of electricity by 2017 through photovoltaic methods by installing solar cells on the roofs of existing and new residential and commercial buildings (see Figure 1). ${ }^{1}$ CSI will "reduce our output of greenhouse gases by 3 million tons," California Governor Arnold Schwarzenegger said in a speech given in October 2006. "That is equivalent to taking one million cars off the road."
Although specific materials technologies are not mandated by the program, photovoltaic systems "are expected to be the common technology to receive incentives" according to the CSI $H_{a n d b o o k}{ }^{2}$ The fact that incentives paid to participants are based on the amount of electricity generated will motivate consumers to adopt the most efficient solar cell technologies, thus increasing the performance level of the "common technology." This should result in significant market pressure to drive competition between photovoltaic cell manufacturers to produce the highest quality product. 